\title{
Real-time monitoring system for weather and air pollutant measurement with HTML-based UI application
}

\author{
Prisma Megantoro $^{1}$, Brahmantya Aji Pramudita ${ }^{2}$, P. Vigneshwaran ${ }^{3}$, Abdufattah Yurianta ${ }^{4}$, Hendra \\ Ari Winarno5 \\ ${ }^{1}$ Faculty of Advanced Technology and Multidiscipline, Universitas Airlangga, Indonesia \\ ${ }^{2}$ School of Electrical Engineering, Telkom University, Indonesia \\ ${ }^{3}$ Department of CSE, SRM Institute of Science \& Technology, Kattankulathur, Chennai, India \\ ${ }^{4}$ Faculty of Science and Technology, Universitas Airlangga, Indonesia \\ ${ }^{5}$ Faculty of Engineering, Universitas Gadjah Mada, Indonesia
}

\section{Article Info \\ Article history: \\ Received Nov 15, 2020 \\ Revised Mar 2, 2021 \\ Accepted Apr 23, 2021}

\section{Keywords:}

Air quality

ESP32

Microcontroller

Weather station

Web application

\begin{abstract}
This article discusses devising an IoT system to monitor weather parameters and gas pollutants in the air along with an HTML web-based application. Weather parameters measured include; speed and direction of the wind, rainfall, air temperature and humidity, barometric pressure, and UV index. On the other side, the gases measured are; ammonia, hydrogen, methane, ozone, carbon monoxide, and carbon dioxide. This article is introducing a technique to send all parameter data. All parameters read by each sensor are converted into a string then joined into a string dataset, where this dataset is sent to the server periodically. On the UI side, the dataset that has been downloaded from the server-parsed for processing and then displayed. This system uses Google Firebase as a real-time database server for sensor data. Also, using the GitHub platform as a web hosting. The web application uses the HTML programming platform. The results of this study indicate that the device operates successfully to provide information about the weather and gases condition as real-time data.
\end{abstract}

This is an open access article under the CC BY-SA license.

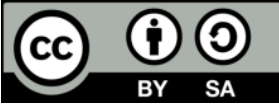

\section{Corresponding Author:}

Prisma Megantoro

Faculty of Advanced Technology and Multidiscipline

Universitas Airlangga

Surabaya, Indonesia

Email: prisma.megantoro@stmm.unair.ac.id

\section{INTRODUCTION}

Today, information system is very important to human life, such as to inform the weather [1], health [2]-[6], warning system, and more. In human daily activities are inseparable from the weather and air conditions in the place where they live and work. This of course will affect health conditions. Especially during the current COVID-19 (corona virus disease 2019) pandemic, environmental conditions are an important concern in maintaining a healthy body. Information about weather conditions can be of great use when considering activities outside the home or office. Besides, information about the levels of pollutant gases in the air is also very important to determine the potential for air pollution which greatly affects the health of the body.

Several studies have been conducted to measure and monitor weather conditions and gas levels in the air, such as the internet of things-based system conducted by Kodali et al. [7]. Weather stations with mobile applications have also been carried out by Munandar et al. [8]. Research on weather station design using a microcontroller board was carried out by Saini et al. [9] and Solano et al. [10], who also used a 
Raspberry Pi board by Savic et al. [11]. There is also research on weather stations used for agricultural purposes that have been done by Navulur et al. [12] and Sekaran et al. [13]. The assessment of weather conditions is also useful for determining the potential of wind energy in Oman, which is described in the AlYahyai article [14]. Mary et al. also aimed to design three generations of the automatic weather station prototype [15].

Different from previous research, the weather station device in this study is equipped with a feature for measuring pollutant gases. This feature is used to obtain data on air quality conditions. This article also introduces the ESP32 data transmission method. Data delivery to a real-time database is done directly every 1 minute. Then the database stores the data in JSON form which can be processed by an HTML-based program. The ESP32 microcontroller board is used to read sensors, process data, upload to the server, and also store data to a micro SD card. Just like its family, the ESP8266 is a microcontroller module type Arduino [16]-[21] which is very suitable for use in automation system applications that utilize the internet network [22]-[26]. Boards based on dual-processor chips made by Espressif are very commonly used on the Internet of Things-based applications such as [27]-[28].

The data obtained is then uploaded to a cloud real-time database and accessed by an HTML-based web application that is hosted on the GitHub platform. The use of web applications to facilitate user access can be done anywhere and anytime. The HTML platform is very suitable to be used for this purpose. The web interface is also made attractive and informative for the users.

\section{PROCEDURE}

This research consists of 3 parts, namely; field-deployed hardware, real-time databases, and web applications. The hardware consists of a power supply, sensors, and a microcontroller. Database using Google Firebase cloud server and web hosting using the GitHub platform. For web monitoring applications using the HTML platform.

\subsection{System design}

Figure 1 explains the design of the system which consists of; sensors, microcontroller, router, and modem are installed on the equipment in the field. They are supplied by a $9 \mathrm{~V}$ adapter. Measurement of weather parameters using an anemometer, wind vane, and rain gauge which is integrated with DHT 11 and BMP sensors in a shield module. This shield module sends data via serial communication to the microcontroller. The data that has been processed is then uploaded to the database server and stored on a micro SD card. From the user's side, a web-based application was created for monitoring all measured parameters. This application can be accessed at the address http://ftmm.unair.ac.id/airfeelproject. Data acquisition on this web application is carried out at a 2-minute interval.

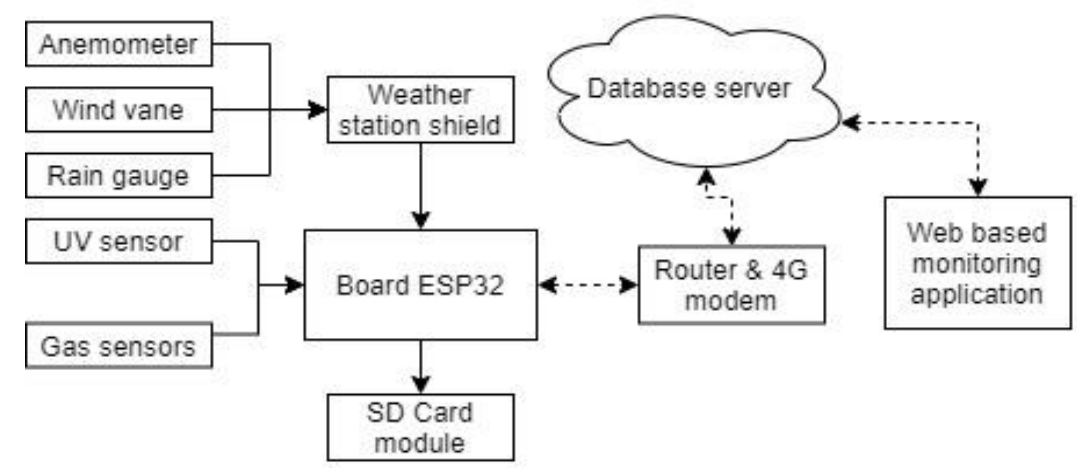

Figure 1. System block diagram

\subsection{Hardware design}

The hardware installed in the field consists of a PCB assembled for the gas sensors, weather station shield, DC/DC step down converter, and the Nodemcu ESP32 development kit C as microcontroller board [29]-[34]. several researchers have also developed various automation systems using various microcontroller boards [35]-[42]. Figure 2 shows the connections between the components used in this field system. There are 4 sensors which have an analog signal output, namely MQ-8, MQ-131, MQ-135, and a UV sensor. The use of the ESP32 board is suitable because it has many pins that can be used as an analog to digital converter (ADC) input. 
Another gas sensor, the Parallax brand, has a digital signal output, namely $\mathrm{CO}$ and $\mathrm{CO} 2$. Their output pins are connected to the general digital pins on the ESP32. Then the MQ-4 sensor has a digital signal output that is sent via i2c communication on the SDA and SCL pins. Then the weather shield sends weather parameter data via serial communication on the TX and RX pins. This device also uses a 16x2 LCD as an indicator of SSID and IP on the Wi-fi network used. All components in this device are supplied by one $9 \mathrm{~V}$ adapter. The power supply is then separated into 2 DC/DC step-down converters for the right voltage specifications for the ESP32 board and sensors.
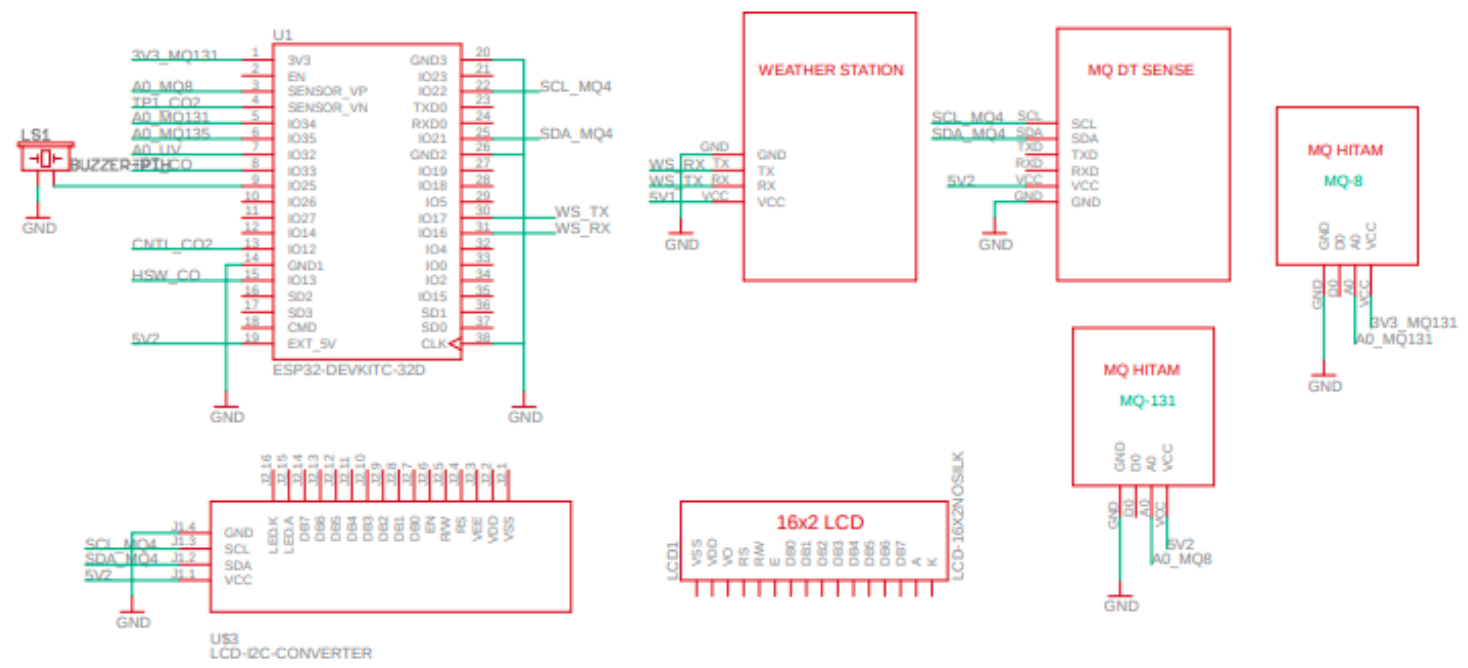

Figure 2. Schematic diagram of the field system device

\subsection{Real-time database}

This study utilizes an open-source facility provided free by Google Firebase. Firebase gives the Real-time database, in Firebase the data is stored as JSON and synchronized continuously to each associated client this means that the client need not has to make a call to fetch data changes, Firebase takes the initiative and notifies the application every time the data is changed this means unless the data at server get changed no call or response will be done which leads to optimum utilization of bandwidth [43]. The feature used in this study is a real-time database. This feature is a cloud-hosted database. A series of datasets are put together in the process on the microcontroller and then sent to the database in the form of a string containing the value of each sensor parameter with a separate comma.

\subsection{Web-based application}

This application is used to observe changes in the value of all measured parameters. Created using HTML programming, there are a total of 13 actual parameters plus 2-time parameters, namely date and time. Especially for time parameters, data is retrieved from the NTP server. This data is taken every measurement made by the microcontroller. Thus, the measurement dataset will always correspond to the actual time in the field.

\section{RESEARCH METHOD}

\subsection{Field station system}

As mentioned in the previous section, all sensors, microcontrollers, and routers are placed in the field for the actual measurement. The placement is on the top of Nanizar Zaman Joenoes Building, Airlangga University, Surabaya, Indonesia. This building has coordinates -7.266329, 112.78436. Installation of the device is on the highest structure in the building which has an altitude of about 80 meters. All of the fieldsets shown in Figure 3 (a) are protected in an aluminum panel. This panel can protect electronic devices from heat and rain. As shown in Figure 3 (b), the anemometer used is a vertical wind turbine that has 3 spoon-shaped lattices to catch the wind. The vertical turbine type makes it capable of catching wind from all directions. A wind vane is used to measure the direction of wind arrival. This fin is used so that the wind vane can rotate in the direction of the wind. Rainfall measurements are made with a rain gauge. As an indicator of the sun's lighting conditions, the S12SD UV sensor is used. 


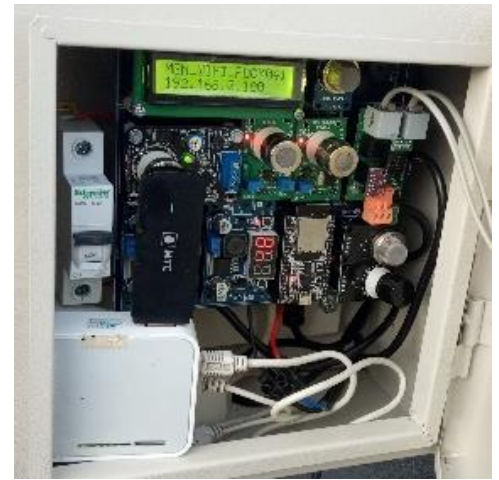

(a)

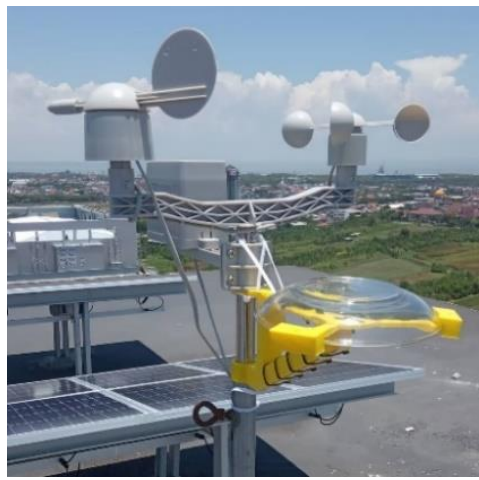

(b)

Figure 3. Installation of the weather station field system on the top of the building, (a) Controller and gas sensors setup, (b) Anemometer, wind vane, rain gauge, and UV sensor probe set up on the field

\subsection{Firmware design}

This firmware is an embedded program that is made as to the operational core of the hardware station field. This program is made with the Arduino IDE. The program workflow embedded in the microcontroller is shown in Figure 4 This program begins with a declaration of all libraries and all variables. Then enter the main program in the infinite loop. In this main program, the process begins with reading all the gas sensors, followed by reading the weather data from the weather station shield. After this, the network is connected again to ensure that the equipment is still connected to the local network. Then the process of parsing all sensor data. All data is concatenated as a comma-separated string. This is done to simplify the data split process in the client application. The data that has been collected from the sensor is then formulated into an equation to produce the actual data unit reading then this dataset is saved to SD in .csv form. The next process is uploading data to a real-time database. If the connection is interrupted and the database responds to a failed upload, the system will reset. But if not, the system work will continue into the loop process. If the loop has occurred 10 times, the system will reset.

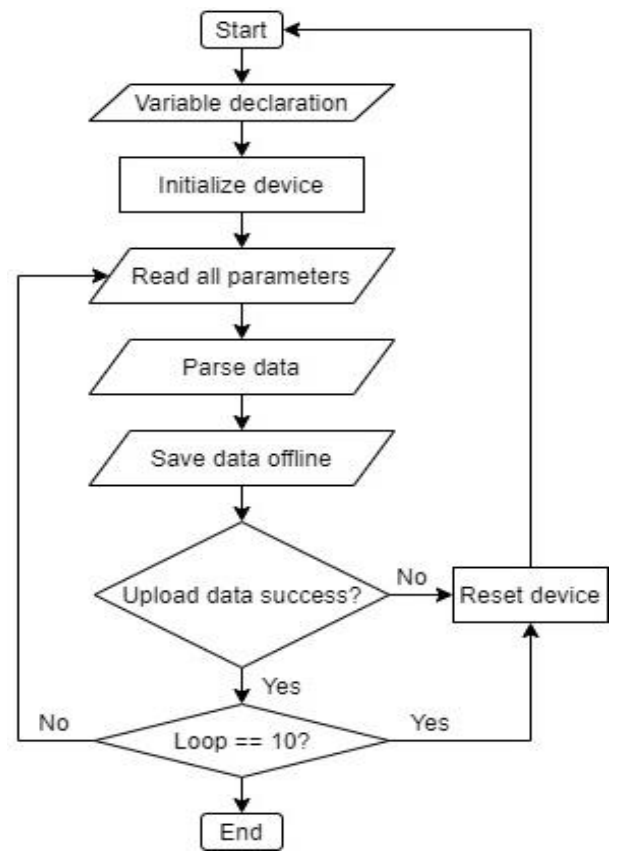

Figure 4. Workflow of the field program

\subsection{Web-based UI (user interface) design}

Figure 5 shows the UI display on a web page created for monitoring weather station devices. All measurement data for weather and air gas parameters are displayed in numerical form. This web application 
design is made attractive and informative, making it easier for users to observe weather conditions and air gas levels around the location of field hardware placement.

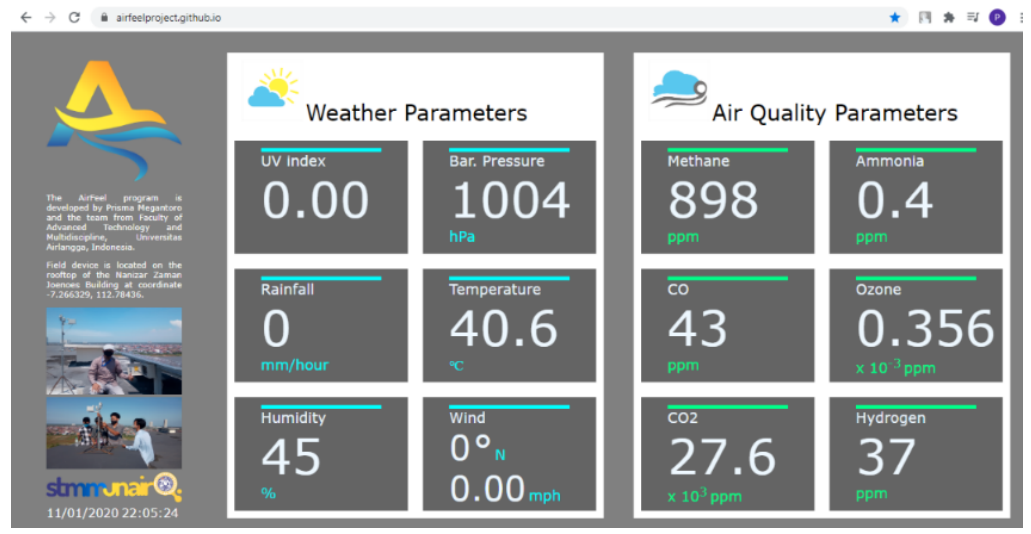

Figure 5. UI real-time display on web browser

\subsection{Data traffic}

The field device will upload the dataset every 1 minute. The data is then stored in a real-time database. Uploaded data is always replaced with data afterward, so this database storage is not permanent, only temporary. In the web application, data requests are made in 2-minute intervals. Each time during this period, the application will request data access data to the real-time database to be displayed in text form on the database web page. Once this data is obtained by the client application, it is then processed and displayed on a web page.

\section{RESULT AND DISCUSSION}

\subsection{Field system work}

This system works well supported by a good internet connection. Internet connection is very dependent on the performance of the router and $4 \mathrm{G}$ modem to get a cellular signal in the field. The voltage supply for each sensor is provided separately in 2 DC/DC step-down converters. Overall, this field device requires an AC supply voltage of $220 \mathrm{~V}$ and a current of around $0.08 \mathrm{~A}$, so the total power for operation of this device is around 17 Watt AC.

\subsection{Monitoring system work}

A survey of the level of interest and informativeness of this monitoring web page has been conducted to assess the quality of the UI designed. The survey results showed that $100 \%$ of 32 correspondents stated that the web monitoring page design was interesting and informative.

\subsection{Data analysis}

The UI web application does the request and receives real-time data at a 2 -minute interval. So normally, all data changes once every 2 minutes. This application requests data to the Firebase server at this interval. Data retrieval on-field device is correct in terms of time. However, data transmission and data reception are highly dependent on the quality of the network connection at the location. There may be network connection interruptions at certain times such as when it rains or the weather is not supportive. This is also influenced by the performance of the $4 \mathrm{G}$ modem and router used. This test was conducted from 10:00 a.m. on November 1, 2020, to 10:00 a.m. on November 2, 2020. Data is taken from SD Card storage. All data is stored in one .csv file.

Figure 6 shows the other 4 weather parameters, including the UV index at the location, Figure 6(a) UV index, 6(b) air ambient temperature, 6(c) humidity, and 6(d) barometric pressure. Mostly it has more than 15 indexes, the change of ambient temperature at location over a day and night, actual humidity, and barometric pressure at the location which has about 90-meter height above the sea level. Figure 7 shows the wind distribution at the location. Most winds come from the North of the location with a $3.2 \mathrm{~m} / \mathrm{s}$ speed on average. 


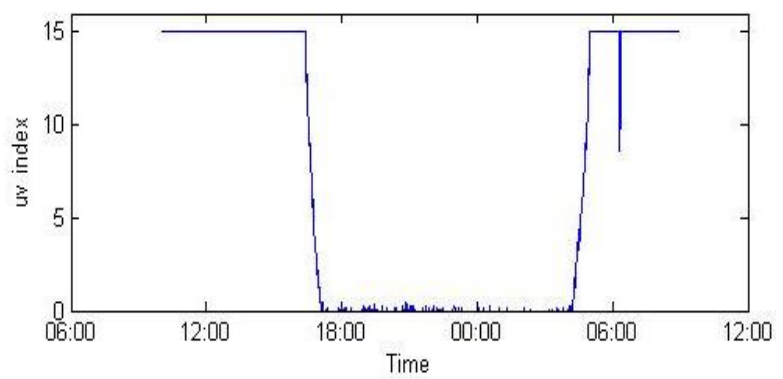

(a)

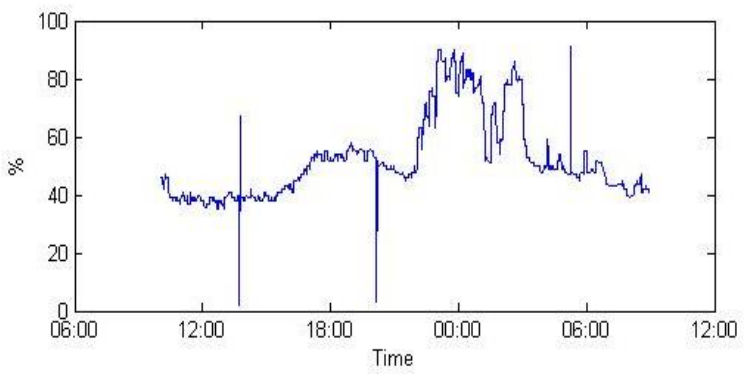

(c)

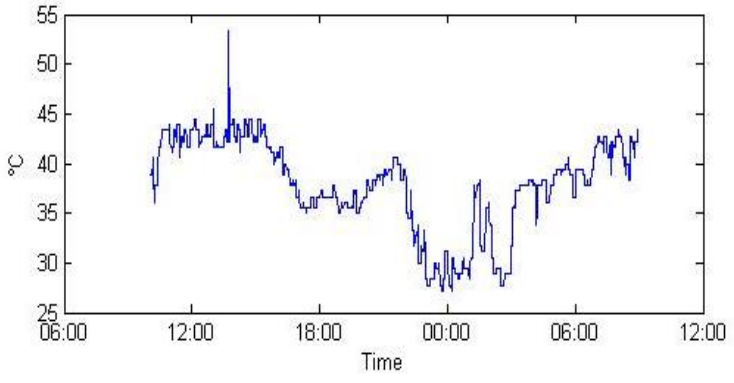

(b)

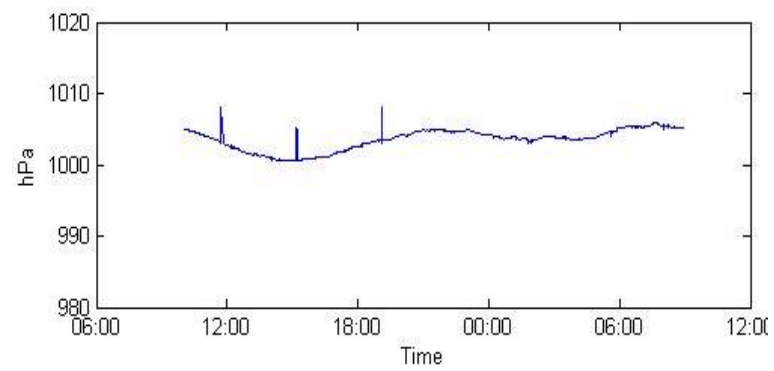

(d)

Figure 6. The weather station sensor readings, (a) UV index, (b) Air ambient temperature, (c) Humidity, and (d) Barometric pressure

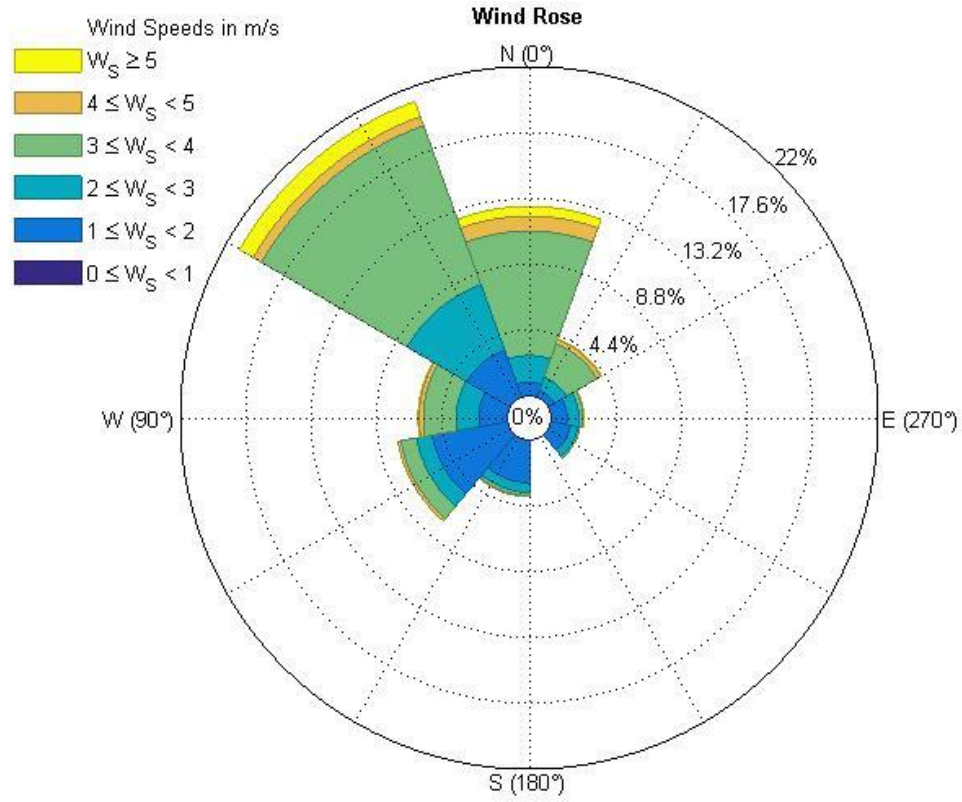

Figure 7. Windrose of direction and speed measurement

Figure 8 shows the changes of each gas composition in the air for over a day and night. The measurement changes follow the actual weather condition and daytime. Based on the real data captured from SD Card, all of the weather parameters will change dramatically when the condition is cloudy and raining. It also happened to gas readings. The changes occur because the composition of the particles in the air also changes. 


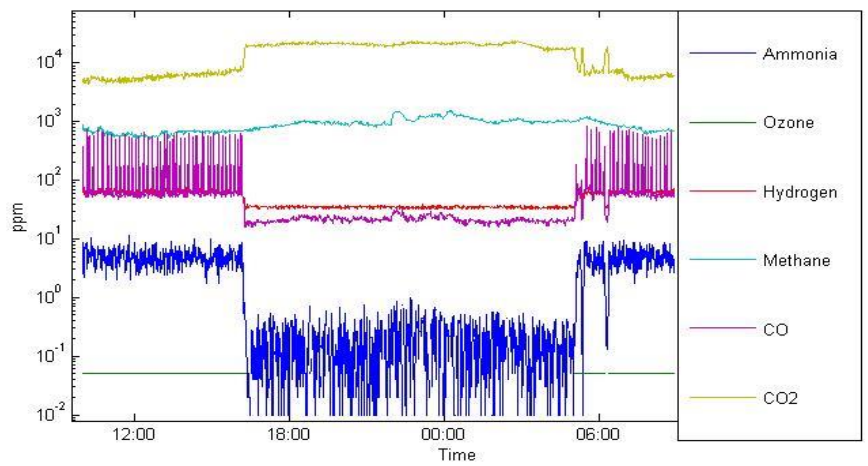

Figure 8. All pollutant gases measurement

\section{CONCLUSION}

The design of a weather station system and measurement of 6 kinds of pollutant gases contained in the air were successfully made to observe actual weather and air condition. The field test shows that all measured weather parameters, including wind direction and speed, rainfall, UV index, air temperature and humidity, and barometric pressure have accurate and reasonable measurement results. The measurement results show changes in the value of the parameters in 1 daily cycle. The value of gas parameters measured in 1 daily cycle also shows a reasonable result. The UI web application is very useful to give real-time information about all parameters every 2 minutes via public network and Firebase. Offline data storage on the SD card can be stored and can be accessed properly for users who want to get measurement history for a certain period. The future direction of improving this proposed study is developing the detection of the severe level of gases in the system and indicating the found level of gases that reach the critical level on the webbased application or smart devices.

\section{ACKNOWLEDGEMENTS}

We are grateful to the Institute for Research and Innovation (LPI), Universitas Airlangga for providing this internal research grant program in 2020. We also thank all colleagues and students of Electrical Engineering and Industrial Engineering from the Faculty of Advanced and Multidisciplinary Technology, Airlangga University for their support for this research.

\section{REFERENCES}

[1] A. H. Hendrawan et al., "Monitoring the Environmental Temperature Using Arduino and Telegram," Journal Robotics and Control (JRC), vol. 1, no. 3, pp. 96-101, 2020, doi: 10.18196/jrc.1321.

[2] A. N. N. Chamim, D. C. Hardyanto, and K. T. Putra, "Web-Based Flood Hazard Monitoring," J. Robot. Control, vol. 2, no. 5, pp. 373-379, 2021, doi: 10.18196/jrc.25110.

[3] E. Loniza, D. C. Dhamayanti, and M. Safitri, "Dehydration level detector through human urine with LED and LDR,” J. Robot. Control, vol. 2, no. 3, pp. 140-144, 2021, doi: 10.18196/jrc.2367.

[4] W. Robson, I. Ernawati, and C. Nugrahaeni, "Design of Multisensor Automatic Fan Control System Using Sugeno Fuzzy Method," J. Robot. Control, vol. 2, no. 4, pp. 302-306, 2021, doi: 10.18196/jrc.2496.

[5] Y. Irawan, A. Febriani, R. Wahyuni, and Y. Devis, "Water Quality Measurement and Filtering Tools Using Arduino Uno, PH Sensor and TDS Meter Sensor," J. Robot. Control, vol. 2, no. 5, 2021, doi: 10.18196/jrc.25107.

[6] N. P. Astuti et al., "Vehicle Security System using Short Message Service ( SMS ) as a Danger Warning in Motorcycle Vehicles," Journal Robot and Control, vol. 1, no. 6, pp. 224-228, 2020, doi: 10.18196/jrc.1642.

[7] R. K. Kodali and S. Mandal, "IoT Based Weather Station," Int. Conf. Control. Instrumentation, Commun. Comput. Technol., pp. 680-683, 2016, doi: 10.1109/ICCICCT.2016.7988038.

[8] A. Munandar, H. Fakhrurroja, M. I. Rizqyawan, R. P. Pratama, J. W. Wibowo, and I. A. F. Anto, "Design of realtime weather monitoring system based on mobile application using automatic weather station," 2017 2nd Int. Conf. Autom. Cogn. Sci. Opt. Micro Electro-Mechanical Syst. Inf. Technol., pp. 44-47, 2017, doi: 10.1109/ICACOMIT.2017.8253384.

[9] H. Saini, A. Thakur, S. Ahuja, N. Sabharwal, and N. Kumar, "Arduino based automatic wireless weather station with remote graphical application and alerts," 3rd Int. Conf. Signal Process. Integr. Networks, SPIN 2016, pp. 605609, 2016, doi: 10.1109/SPIN.2016.7566768. 
[10] G. Solano, F. Lama, J. Terrazos, and J. Tarrillo, "Weather station for educational purposes based on Atmega8L," 2017 IEEE XXIV International Conference on Electronics, Electrical Engineering and Computing (INTERCON), 2017, doi: 10.1109/INTERCON.2017.8079728.

[11] T. Savic and M. Radonjic, "One approach to weather station design based on Raspberry Pi platform," 2015 23rd Telecommun. Forum, TELFOR 2015, pp. 623-626, 2016, doi: 10.1109/TELFOR.2015.7377544.

[12] S. Navulur, A. S. C. S. Sastry, and M. N. Giri Prasad, "Agricultural management through wireless sensors and internet of things," Int. J. Electr. Comput. Eng., vol. 7, no. 6, pp. 3492-3499, 2017, doi: 10.11591/ijece.v7i6.pp3492-3499.

[13] K. Sekaran, M. N. Meqdad, P. Kumar, S. Rajan, and S. Kadry, "Smart agriculture management system using internet of things," Telkomnika (Telecommunication Comput. Electron. Control), vol. 18, no. 3, pp. 1275-1284, 2020, doi: 10.12928/TELKOMNIKA.v18i3.14029.S.

[14] AL-Yahyai, Y. Charabi, A. Gastli, and S. Al-Alawi, "Assessment of wind energy potential locations in Oman using data from existing weather stations," Renew. Sustain. Energy Rev., vol. 14, no. 5, pp. 1428-1436, 2010, doi: 10.1016/j.rser.2010.01.008.

[15] M. Nsabagwa, M. Byamukama, E. Kondela, and J. S. Otim, "Towards a robust and affordable Automatic Weather Station," Dev. Eng., vol. 4, 2019, doi: 10.1016/j.deveng.2018.100040.

[16] R. T. Yunardi, D. Arifianto, F. Bachtiar, and J. I. Prananingrum, "Holonomic Implementation of Three Wheels Omnidirectional Mobile Robot using DC Motors," J. Robot. Control, vol. 2, no. 2, 2021, doi: 10.18196/jrc.2254.

[17] A. Beltran Jr, K. J. Dizon, K. Nones, R. L. Salanguit, J. Bhie Santos, and J. Rei Santos, "Arduino-based Disaster Management System,” J. Robot. Control, vol. 2, no. 1, pp. 24-28, 2020, doi: 10.18196/jrc.2147.

[18] Y. Irawan, R. Wahyuni, and H. Herianto, "Morse Code Receiver On Invisible Light Using Background Subtraction Method," J. Robot. Control, vol. 2, no. 4, pp. 283-286, 2021, doi: 10.18196/jrc.2492.

[19] U. Rahmalisa, A. Febriani, and Y. Irawan, "Detector Leakage Gas Lpg Based On Telegram Notification Using Wemos D1 and Mq-6 Sensor," J. Robot. Control, vol. 2, no. 4, pp. 287-291, 2021, doi: 10.18196/jrc.2493.

[20] S. Purwanti, A. Febriani, M. Mardeni, and Y. Irawan, "Temperature Monitoring System for Egg Incubators Using Raspberry Pi3 Based on Internet of Things (IoT)," J. Robot. Control, vol. 2, no. 5, 2021, doi: 10.18196/jrc.25105.

[21] Y. Irawan, M. Muhardi, R. Ordila, and R. Diandra, "Automatic Floor Cleaning Robot Using Arduino and Ultrasonic Sensor," J. Robot. Control, vol. 2, no. 4, pp. 4-7, 2021, doi: 10.18196/jrc.2485.

[22] S. Widadi, S. A. B. Munir, N. Shahu, I. Ahmad, and I. Al Barazanchi, "Automatic Wireless Nurse Caller," J. Robot. Control, vol. 2, no. 5, pp. 380-384, 2021, doi: 10.18196/jrc.25111.

[23] M. V. S. Rao and M. Shivakumar, "IR Based Auto-Recharging System for Autonomous Mobile Robot," J. Robot. Control, vol. 2, no. 4, 2021, doi: 10.18196/jrc.2486.

[24] A. Bhawiyuga, D. P. Kartikasari, K. Amron, O. B. Pratama, and M. W. Habibi, "Architectural design of IoT-cloud computing integration platform," Telkomnika (Telecommunication Comput. Electron. Control, vol. 17, no. 3, pp. 1399-1408, 2019, doi: 10.12928/TELKOMNIKA.V17I3.11786.

[25] S. Sachdev, J. Macwan, C. Patel, and N. Doshi, "ScienceDirect Voice-Controlled Autonomous Vehicle VoiceControlled Autonomous Vehicle Using Using IoT IoT," Procedia Comput. Sci., vol. 160, pp. 712-717, 2019, doi: 10.1016/j.procs.2019.11.022.

[26] L. Kuncoro and P. Saputra, "Implementation of Air Conditioning Control System," 2017 International Conference on Smart Cities, Automation \& Intelligent Computing Systems (ICON-SONICS), pp. 126-130, 2020, doi: 10.1109/ICON-SONICS.2017.8267834.

[27] K. Luechaphonthara and A. Vijayalakshmi, "IOT based application for monitoring electricity power consumption in home appliances," Int. J. Electr. Comput. Eng., vol. 9, no. 6, pp. 4988-4992, 2019, doi: 10.11591/ijece.v9i6.pp49884992.

[28] A. H. Ali, A. H. Duhis, N. A. Lafta Alzurfi, and M. J. Mnati, "Smart monitoring system for pressure regulator based on IOT," Int. J. Electr. Comput. Eng., vol. 9, no. 5, pp. 3450-3456, 2019, doi: 10.11591/ijece.v9i5.pp3450-3456.

[29] A. Latif, H. A. Widodo, R. A. Atmoko, T. N. Phong, and E. T.Helmy, "Temperature and Humidity Controlling System for Baby Incubator,” J. Robot. Control, vol. 2, no. 3, pp. 190-193, 2021, doi: 10.18196/jrc.2376.

[30] D. U. Rijalusalam and I. Iswanto, "Implementation Kinematics Modeling and Odometry of Four Omni Wheel Mobile Robot on The Trajectory Planning and Motion Control Based Microcontroller," J. Robot. Control, vol. 2, no. 5, pp. 448-455, 2021, doi: 10.18196/jrc.25121.

[31] R. Perkasa, R. Wahyuni, R. Melyanti, H. Herianto, and Y. Irawan, "Light Control Using Human Body Temperature Based on Arduino Uno and PIR (Passive Infrared Receiver) Sensor,” J. Robot. Control, vol. 2, no. 4, pp. 307-310, 2021, doi: 10.18196/jrc.2497.

[32] Iswanto, P. Megantoro, and D. V. Senzas, "Calibrator for Temperature Measurement Device with Raspberry PiBased Interface,” Int. J. Innov. Technol. Explor. Eng., vol. 8, no. 12, pp. 4862-4866, 2019.

[33] I. Iswanto, A. Nurjanah, I. Prasojo, F. Anindiyahadi, and N. M. Raharja, "Mosque as a Civilization Center," Int. J. Innov. Technol. Explor. Eng., vol. 8, no. 12, pp. 1072-1074, Oct. 2019, doi: 10.35940/ijitee.K2345.1081219.

[34] A. N. N. Chamim, M. E. Fawzi, Iswanto, R. O. Wiyagi, and R. Syahputra, "Control of wheeled robots with bluetooth-based smartphones," Int. J. Recent Technol. Eng., vol. 8, no. 2, pp. 6244-6247, 2019, doi: 10.35940/ijrte.B3352.078219.

[35] D. Hardiyanto, I. Iswanto, D. A. Sartika, and M. Rojali, "Pedestrian Crossing Safety System at Traffic Lights based on Decision Tree Algorithm," Int. J. Adv. Comput. Sci. Appl., vol. 10, no. 8, pp. 375-379, 2019, doi: 10.14569/IJACSA.2019.0100850. 
[36] I. Iswanto, K. Purwanto, W. Hastuti, A. Prabowo, and M. Y. Mustar, "Smart Smoking Area based on Fuzzy Decision Tree Algorithm," Int. J. Adv. Comput. Sci. Appl., vol. 10, no. 6, pp. 500-504, 2019.

[37] A. N. N. Chamim, D. Ahmadi, and Iswanto, "Atmega16 Implementation As Indicators Of Maximum Speed," Int. J. Appl. Eng. Res., vol. 11, no. 15, pp. 8432-8435, Jun. 2016.

[38] A. N. N. Chamim, M. Heru Gustaman, N. M. Raharja, and I. Iswanto, "Uninterruptable Power Supply based on Switching Regulator and Modified Sine Wave," Int. J. Electr. Comput. Eng., vol. 7, no. 3, pp. 1161-1170, Jun. 2017, DOI: 10.11591/ijece.v7i3.pp1161-1170.

[39] Iswanto, J. Syaftriadi, A. Nur, N. Chamim, R. O. Wiyagi, and R. Syahputra, "LED and Servo Motor Control Via Bluetooth Based on Android Applications,” Int. J. Recent Technol. Eng., vol. 8, no. 2, pp. 6227-6231, Jul. 2019.

[40] I. Iswanto, W. S. Agustiningsih, F. Mujaahid, R. Rohmansyah, and A. Budiman, "Accumulator Charging Control with Piezoelectric Based on Fuzzy Algorithm Scheduling," TELKOMNIKA (Telecommunication Comput. Electron. Control), vol. 16, no. 2, pp. 635-640, Apr. 2018, DOI:10.12928/TELKOMNIKA.v16i2.7067.

[41] Iswanto, S. Suripto, F. Mujahid, K. T. Putra, N. P. Apriyanto, and Y. Apriani, "Energy Harvesting on Footsteps Using Piezoelectric based on Circuit LCT3588 and Boost up Converter," Int. J. Electr. Comput. Eng., vol. 8, no. 6, pp. 4104-4110, 2018, DOI: 10.11591/ijece.v8i6.pp4104-4110.

[42] K. Purwanto, Iswanto, T. K. Hariadi, and M. Y. Muhtar, "Microcontroller-based RFID, GSM and GPS for motorcycle security system," Int. J. Adv. Comput. Sci. Appl., vol. 10, no. 3, pp. 447-451, 2019.

[43] M. C. Wadkar and P. P. Patil, "Traditional Infrastructure vs. Firebase Infrastructure," Int. J. Trend Sci. Res. Dev., vol. 2, no. 4, pp. 2050-2053, 2018, doi: 10.31142/ijtsrd14550.

\section{BIOGRAPHIES OF AUTHORS}
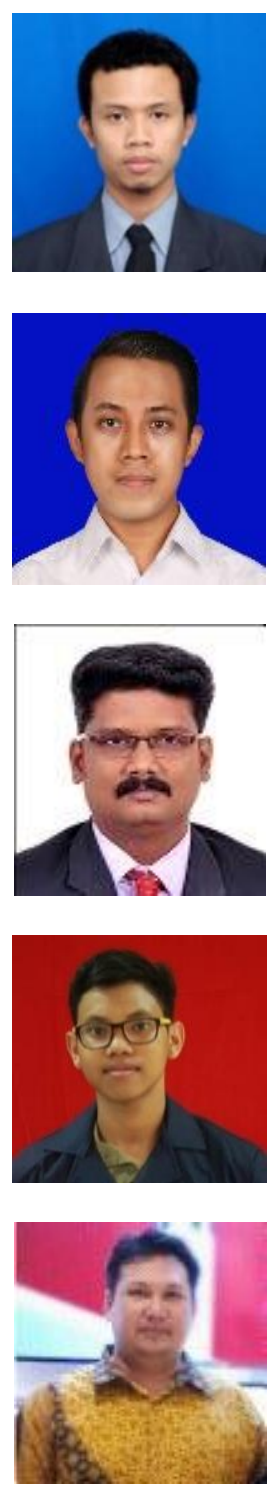

Prisma Megantoro is a lecturer in Electrical Engineering, School of Advanced Technology, and Multidiscipline, Universitas Airlangga since 2020. He received a bachelor's degree and master's degree from Universitas Gadjah Mada, Yogyakarta, Indonesia in 2014 and 2018. His current research is focused on solar photovoltaic technology, embedded system, and the internet of things.

Brahmantya Aji Pramudita is a lecturer in Electrical Engineering, School of Electrical Engineering, Telkom University since 2020. He received a bachelor's degree and master's degree from Universitas Gadjah Mada, Yogyakarta, Indonesia in 2015 and 2018. His research interest includes instrumentation, digital signal processing, and biomedical engineering.

P Vigneshwaran has obtained his Doctoral Degree in Anna University Chennai in 2016 and Master of Engineering under Anna University Chennai in June 2005. He is having 18.4 years of experience and specialization in Cybersecurity. Presently, He is working as Associate Professor at the SRM Institute of Science and Technology, Chennai. He has published more than 18 papers in various international journals and 5 in International Conferences. His area of interest includes Security, Routing, and Intelligent Data Analysis.

Abdufattah Yurianta is a student in Biomedical Engineering, Faculty of Science and Technology, Airlangga University, since 2018. He born in Surabaya, 5 September 2000, and lived in Surabaya since then. He focused on medical instrumentation.

Hendra Ari Winarno is taking a master degree programme in Department of Electrical Engineering and Information Technology, Faculty of Engineering, Universitas Gadajah Mada. His bachelor degree graduated from Universitas Muhammadiyah Gresik. He research focused on electronics, biomedical, internet of things, and PLC. 